\title{
Orbital Schwannoma: Case Report and Review
}

\section{Schwannoma de Órbita: Relato de caso e revisão}

\author{
Ricardo Lourenço Caramanti ${ }^{1}$ Mário José Goes ${ }^{2}$ Feres Chaddad ${ }^{3}$ Lucas Crociati Meguins ${ }^{2}$ \\ Dionei Freitas de Moraes ${ }^{2}$ Raysa Moreira Aprígio ${ }^{2}$ Sérgio Ivo Calzolari ${ }^{2}$ Carlos Eduardo Rocha ${ }^{2}$ \\ Sebastião Carlos da Silva Jr. ${ }^{2}$
} ${ }^{1}$ Centro do Cerebro e Coluna, São José do Rio Preto, SP, Brazil
2 Neurosurgery Department, Faculdade de São José do Rio Preto, São
José do Rio Preto, SP, Brazil
3 Vascular Neurosurgery Department, Universidade de São Paulo, São
Paulo, SP, Brazil
Address for correspondence Ricardo Lourenço Caramanti, MD, Hospital de Base de São José do Rio Preto, Av. Brigadeiro Faria Lima, 5544, São José do Rio Preto, SP, Brazil, 15090-500

(e-mail: rcaramanti@hotmail.com).

\begin{abstract}
Keywords

- orbit

- schwannoma

- extraconal tumor

\section{Resumo}

Palavras-chave

- órbita

- schwannoma

- tumor extraconal

Orbital schwannomas are rare, presenting a rate of incidence between 1 and $5 \%$ of all orbital lesions. Their most common clinical symptoms are promoted by mass effect, such as orbital pain and proptosis. The best complementary exam is the magnetic resonance imaging (MRI), which shows low signal in $\mathrm{T} 1$, high signal in $\mathrm{T} 2$, and heterogeneous contrast enhancement. The treatment of choice is surgical, with adjuvant radiotherapy if complete resection is not possible. We report the case of a 24-year-old male patient with orbital pain and proptosis, without previous history of disease. The MRI showed a superior orbital lesion compatible with schwannoma, which was confirmed by biopsy after complete resection using a fronto-orbital approach.

Schwannomas de órbita são raros, apresentando incidência entre 1 e $5 \%$ de todas as lesões de órbita. Seus sinais clínicos mais comuns são causados pelo efeito de massa da lesão, estando entre eles a dor orbitária e proptose. O melhor exame complementar é a ressonância magnética (MRI) que mostra uma lesão hipointensa em T1, hiperintensa em T2 e de captação heterogênea de contraste. O tratamento de escolha é cirúrgico, com uso de radioterapia adjuvante quando a ressecção completa não for possível. Neste estudo, relatamos, um paciente masculino de 24 anos com dor orbitária e proptose, sem historia de doenças prévias. A ressonância mostrou uma lesão na região superior da órbita comparável com um schwannoma, que foi confirmada por biópsia após a completa ressecção usando um acesso fronto orbitário.
\end{abstract}

\section{Introduction}

Schwannomas are slow-growth benign tumors, which normally originate from a sensitive nerve sheath. Among the cranial nerves, the vestibule-cochlear is most commonly affected one, with an incidence of 8 to $10 \%$ of all intracranial tumors. $^{1-3}$

received

January 8, 2019

accepted

May 27, 2019
DOI https://doi.org/

10.1055/s-0039-1693683. ISSN 0103-5355.
Orbital schwannomas are rarely described in the literature, presenting between 1 and $5 \%$ of all orbital neoplasms. The orbital nerves more commonly involved are trigeminal branches, like the supratrochlear and supraorbital nerves. ${ }^{1,4}$

The most important orbital schwannoma clinical symptoms are orbital pain and proptosis, which are promoted by progressive mass effect. For this reason, small tumors are

Copyright $\odot 2019$ by Thieme Revinter Publicações Ltda, Rio de Janeiro, Brazil

\section{License terms}

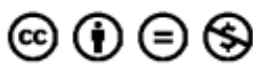






Fig. 1 A and B - Magnetic resonance imaging: axial T1 gadolinium sequence showing a right orbit lesion, superior to eye with heterogeneous enhancement. C - Coronal T2 sequence showing the relationship between the tumor and the right eye. D - Coronal T1 sequence that evidences the tumor and its disposition, lateral and superior to the optic nerve.

frequently asymptomatic for a long time until they become large enough for symptoms to appear. ${ }^{5}$

Surgical approaches can vary with tumor location, and they can be transcranial, facial, or endoscopic.

In the present study, we describe the case of a young male with orbital schwannoma and discuss this pathology.

\section{Case Report}

We report the case of a 24-year-old male patient who presented with a 2-year history of progressive pressure frontal headache and enlarging mass on the right upper eyelid. Two months before hospital admission, he noticed worsening of the vision. There was no report about family cancer or medications in use. Physical examination showed right eye proptosis and lateral inferior dislocation. There were diplopy and right visual field impairment; however, the extrinsic ocular movements and pupillary reactions were preserved.
The orbital MRI evidenced a mass with major dimensions of $3.1 \times 2.5 \times 1.5 \mathrm{~cm}$ located above the right eye. It had a high intensity signal on T2-weighted images, a low intensity on T1-weighted images, and heterogeneous contrast enhancement. (-Fig. 1)

Due to the large size of the lesions and its localization, the transcranial approach was chosen. The incision was arcuate, starting from the superior rim of the zygomatic arch to the midline of the skull in the frontal region and ending back at the hairline because patient expressed the desire to avoid a scar on his face.

A fronto-orbital craniotomy provided a good superior and lateral orbital exposition. The mass was encapsulated and attached to the supraorbital nerve. In the next step, a delicate dissection from orbital fat, nerves, and muscles was made, allowing the "en bloc" resection.

After a complete tumor resection and rigorous hemostasis, the orbit and bone flap were closed with the help of titanium plates and bone cement. 


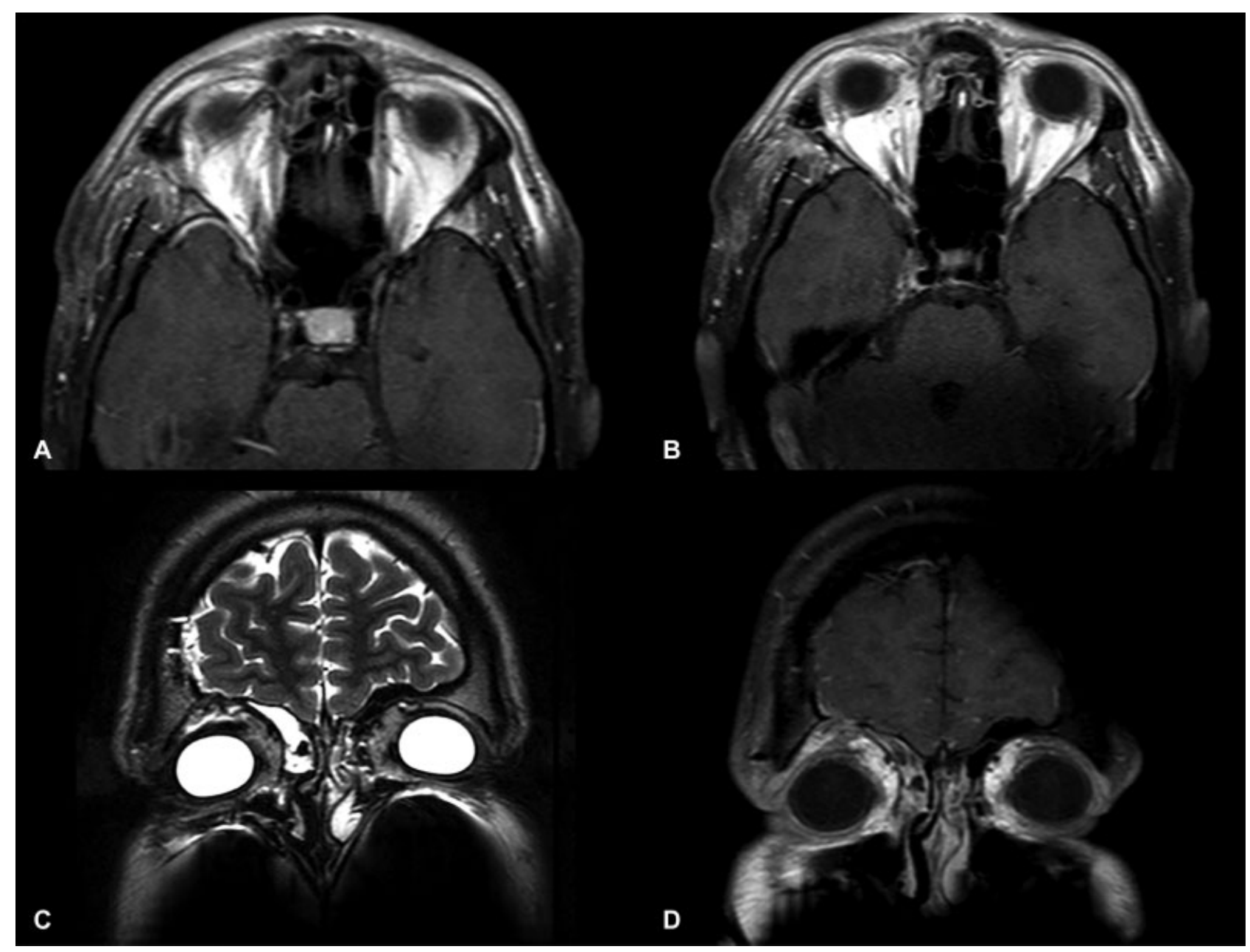

Fig. 2 Postoperative axial and coronal magnetic resonance imaging showing a complete tumor resection with eye symmetry return and preservation of orbital structures.

The postoperative period occurred without complications. Fifteen days after the surgery, the patient showed campimetry with progressive improvement of the visual field. Physical examination presented symmetric ocular globes, without diplopia, facial sensibility, palpebral elevation, or extrinsic ocular muscles alterations. An orbital MRI confirmed complete resection of the lesion, and the pathological definitive study revealed a grade I schwannoma with a ki-67 of $2 \%$. (-Fig. 2 ).

\section{Discussion}

Orbital schwannomas are rare, presenting frequency between 1 and $5 \%$ of all orbit neoplasms, with age variation from 20 to 70 years old and without gender prevalence. ${ }^{1-3,6}$

In general, schwannomas originate from sensory nerves. In the case of orbital schwannomas, it is not different, with the supratrochlear and supraorbital nerves being the ones most frequently affected. This explains the delay in affecting the vision and extraocular movements, which occurs late in the clinical presentation. Although less common, nerves like the oculomotor, trochlear, and abducens can be affected and must be suspected if there are eye movement deficits without previous symptoms. ${ }^{7}$
The most common symptoms are caused by orbital structures compression, which include orbital pain and proptosis, as reported by our patient during the clinical examination. Other symptoms, in decreasing order of frequency, are diplopia, visual acuity decrease, facial hypoesthesia, and headache. ${ }^{5-9}$

It is difficult to identify the origin of the tumor during surgery, because there is a large volume of fat and many nerve fibers crossing the orbit. We believe that the clinical examination is a good way to identify the nerve of origin of the tumor. ${ }^{7-9}$

The complementary examination involves computer tomography (CT) of the brain, which can show an isodense image in relation to the orbital muscles, orbital bone enlargement and bone deformities. Magnetic resonance imaging is the preferred imaging exam due to its elevated sensibility. The orbital schwannoma has low intensity in $\mathrm{T} 1$ and high intensity in $\mathrm{T} 2$ sequences and has regular contours. It commonly have a heterogeneous appearance, enhanced by gadolinium which allows your distinction from the homogeneous pattern exhibited by cavernous hemangiomas. Orbital lymphomas may be similar to schwannomas regarding shape and location, but they present intermediate signal in T2-sequence and adapt to the surrounding structures, unlike the schwannoma, which may distort the anatomy of adjacent structures. ${ }^{8,10-12}$ 
Anatomically, the orbit should be imagined as an irregular pyramid with four sides.

Lesions located in the superior half of the orbit can be accessed by orbital roof with a frontotemporal approach. If a lateral to medial vision is needed, the orbitotomy should be added to the approach. In cases of lateral inferior tumors, a lateral orbitotomy called Burke-Kronlein, with or without zygomatic osteotomy, can be used. ${ }^{13,14}$

To access the medial inferior quadrant of the orbit, one option is endoscopic access, which has the advantage of being less invasive than the transcranial route. ${ }^{13-15}$

For small lesions located in the anterior half of the orbit, approaches without osteotomies, like eyelid superiorly or subciliary and orbital rim inferiorly can be tried. The disadvantage of anterior approaches is a restricted vision field which promotes difficulties in locating and preserve the anatomical structures. ${ }^{13-15}$

In our case, we choose a transcranial fronto-orbital approach to get more space to work due to a big size presented by tumor in relation to patient orbit.

When complete resection is not possible, adjuvant radiotherapy can be considered. ${ }^{16}$

\section{Conclusion}

Orbit schwannoma is a rare tumor, which generates mainly mass effect as clinical presentation. The standard treatment is surgery-based, with complete excision whenever possible. The approach can vary according with the location of the tumor, depending from orbital anatomical side and need to be individualized.

Conflitos de Interesse

The authors declare that there are no conflicts of interest.

\section{References}

1 Iida Y, Sakata K, Kobayashi N, Tatezuki J, Manaka H, Kawasaki T. Orbital Abducens Nerve Schwannoma: A Case Report and Review of the Literature. NMC Case Rep J 2016;3(04):107-109. Doi: 10.2176/nmccrj.cr.2015-0259

2 Mahore A, Ramdasi R, Chagla A, Tikeykar V. Intraconal optic sheath schwannoma: report of two cases. Br J Neurosurg 2019; 33(01):101-103. Doi: 10.1080/02688697.2017.1297768
3 Nesvick CL, Perry A, Graffeo CS, Raghunathan A, Hammack JE, Van Gompel JJ. Trochlear Schwannoma Presenting with Isolated Trigeminal Neuralgia. World Neurosurg 2017;103:951.e13-951.e20. Doi: 10.1016/j.wneu.2017.04.062

4 Barhmi I, Mahdoufi R, Khallouq A, et al. Uncommon presentation of orbital schwanomma: A case report. Int J Surg Case Rep 2016; 26:173-175. Doi: 10.1016/j.ijscr.2016.07.045

5 Pushker N, Khurana S, Kashyap S, et al. Orbital schwannoma: a clinicopathologic study. Int Ophthalmol 2015;35(04):481-486. Doi: 10.1007/s10792-014-9973-1 [published Online First: 2014/ 07/24]

6 Garg R, Dhawan A, Gupta N, D'souza P. A rare case of benign isolated schwannoma in the inferior orbit. Indian J Ophthalmol 2008;56(06):514-515. Doi: 10.4103/0301-4738.43380

7 Kim KS, Jung JW, Yoon KC, Kwon YJ, Hwang JH, Lee SY. Schwannoma of the Orbit. Arch Craniofac Surg 2015;16(02):67-72. Doi: 10.7181/acfs.2015.16.2.67 [published Online First: 2015/08/01]

8 Young SM, Kim YD, Jeon GS, Woo KI. Orbital Frontal Nerve Schwannoma-Distinctive Radiological Features. Am J Ophthalmol 2018;186:41-46. Doi: 10.1016/j.ajo.2017.11.012 [published Online First: 2017/12/05]

9 Brucoli M, Giarda M, Arcuri F, Benech A. A benign isolated schwannoma of the orbit. J Craniofac Surg 2011;22(06):2372-2374. Doi: 10.1097/SCS.0b013e318231e4f2 [published Online First: 2011/12/03]

10 Wang Y, Xiao LH. Orbital schwannomas: findings from magnetic resonance imaging in 62 cases. Eye (Lond) 2008;22(08):1034-1039. Doi: 10.1038/sj.eye.6702832 [published Online First: 2007/04/28]

11 Rootman J, Goldberg C, Robertson W. Primary orbital schwannomas. Br J Ophthalmol 1982;66(03):194-204 [published Online First: 1982/03/01]

12 Khan SN, Sepahdari AR. Orbital masses: CT and MRI of common vascular lesions, benign tumors, and malignancies. Saudi J Ophthalmol 2012;26(04):373-383

13 Montano N, Lauretti L, D'Alessandris QG, et al. Orbital Tumors: Report of 70 Surgically Treated Cases. World Neurosurg 2018; 119:e449-e458. Doi: 10.1016/j.wneu.2018.07.181 [published Online First: 2018/08/03]

14 Bachelet JT, Shipkov H, Breton P, Berhouma M, Jouanneau E, Gleizal A. [Surgical approaches of tumors of the posterior cone of the orbit]. Rev Stomatol Chir Maxillofac Chir Orale 2016;117 (02):89-95. Doi: 10.1016/j.revsto.2016.01.005

15 Ellis E III. Surgical approaches to the orbit in primary and secondary reconstruction. Facial Plast Surg 2014;30(05): 537-544. Doi: 10.1055/s-0034-1394100 [published Online First: 2014/11/15]

16 Ramey WL, Arnold SJ, Chiu A, Lemole M. A Rare Case of Optic Nerve Schwannoma: Case Report and Review of the Literature. Cureus 2015;7(04):e265. Doi: 10.7759/cureus.265 